\title{
Beta alanine effects immediately pre- and post hatch on chick quality, carcass yield and meat quality in broilers
}

\author{
H. Atan \& C. Kop-Bozbay \\ Department of Animal Science, Faculty of Agriculture, Eskisehir Osmangazi University, 26480, Eskisehir, Turkey
}

(Submitted 1 October 2020; Accepted 12 December 2020; Published 11 January 2021)

\begin{abstract}
Copyright resides with the authors in terms of the Creative Commons Attribution 4.0 South African Licence.
See: http://creativecommons.org/licenses/by/4.0/za

Condition of use: The user may copy, distribute, transmit and adapt the work, but must recognise the authors and the South African Journal of Animal Science.
\end{abstract}

\begin{abstract}
First, this study aimed to evaluate the effects on hatchability of in ovo supplementation of beta alanine $(\beta A)$. Second, it assessed the effects on performance, meat quality and serum constituents of broiler chickens of $\beta A$ injection in ovo and of supplementation with $\beta A$ in feed for the first seven days after hatching. For this purpose, 960 fertilized broiler chicken eggs were distributed to hatchery trays in four treatment groups with six replicates on day 17 of incubation. The treatment groups consisted of eggs that were not injected (T1; negative control), injected with sterile solution with $0.9 \%$ salt (T2; positive control), injected with in ovo $1 \% \beta A$ solution (T3), and not injected, but with chicks were fed $1 \% \beta A$ for the first seven days after hatching (T4). Upon hatching, chicks from T1, T2, and T3 were fed commercial starter feed. All treatments were assessed with six replicates of 28 birds (14 females and 14 males) throughout the grow-out period. As a result of this study, T3 increased hatchability, yolk-free hatching weight and chick quality, and decreased yolk weight and feed access time at hatch. Both T3 and T4 improved carcass yield and meat quality, and T3 increased serum total antioxidant status at 42 days afer hatching. The results demonstrated that in ovo $\beta A$ feeding improved hatching characteristics, and $\beta A$ administration in ovo or in feed improved carcass yield and meat quality without affecting growth performance.
\end{abstract}

Keywords: antioxidant status, in ovo, oxidant status

${ }^{\#}$ Corresponding author: cbozbay@ogu.edu.tr

\section{Introduction}

Productivity in poultry depends on embryonic development, post-hatch growth, meat production and egg yield. The periods immediately pre- and post hatch are critical to achieving production efficiency, and early supplementation strategies can be beneficial (Sirsat et al., 2018). Studies have shown in ovo (Kadam et al., 2008; Elwan et al., 2019; Kop-Bozbay \& Ocak, 2019; Tavaniello et al., 2020) and post-hatch amino acid feeding (Kralik et al., 2014, 2015; Kop-Bozbay \& Ocak, 2020) to be effective in meeting the nutrient requirements of birds around the time of hatching and to reduce the detrimental consequences that are associated with the hatching process.

Carnosine is a dipeptide molecule that is composed of the amino acids beta-alanine and histidine. Its synthesis depends on the presence of $\beta A$ as a substrate. The concentration of carnosine in the skeletal muscles of animals depends on the species, age, muscle type, nutritional status and, significantly, the composition of the diet (Wu, 2020). The main sources of carnosine and anserine for humans are poultry, beef and fish. White muscle fibres of chickens contain a high concentration of carnosine (Tomonaga et al., 2006). Carnosine and its derivative anserine serve as antioxidants and neurotransmitters. Carnosine has an antioxidative effect because of its ability to bind metal ions and eliminate various types of free radicals (Kralik et al., 2014). This antioxidant activity of carnosine can increase the stability of meat in storage. Moreover, because carnosine has hypoglycemic, hypotensive, antidepressant-like activity and anti-ageing effects, it contributes to the nutritional quality of meat (Boldyrev et al., 2013).

The concentration of carnosine in animal and human tissues can be altered with supplementation of the amino acids that are components of carnosine, namely $\beta A$ and I-Histidine (Tomonaga et al., 2005; Boldyrev et al., 2013). However, carnosine supplementation may not be effective because it is broken down into and during digestion (about $40 \% \beta A$ by weight). In another study, in ovo $\beta A$ feeding had positive effects on the weight of chicks at hatching and on their mobility (Kop-Bozbay et al., 2018). However, although there 
are some studies on dietary $\beta A$ (Tomonaga et al., 2005, 2006, 2012; Kralik et al., 2014, 2015; Qi et al., 2018) in poultry, there is a gap in the literature in which $\beta A$ supplementation in ovo and early post hatch have not been studied simultaneously.

Administration of $\beta A$ in ovo or in feed may enhance the commercial value of broiler chickens by improving the shelf-life of the meat and its nutritional quality because of an increased concentration of these dipeptides in the muscles. Therefore, this study was conducted to determine the effects of i) in ovo $\beta A$ injection on hatchability characteristics, namely hatching weight, yolk weight, hatchability, embryonic mortality rate, chick quality score, and feeding behaviour, and ii) supplementation of $\beta A$ during the first seven days after hatching on the performance, meat quality and serum constituents of broiler chickens.

\section{Materials and Methods}

All procedures with animals were approved by the Animal Experiments Local Ethics Committee of Eskisehir Osmangazi University (Protocol no. HADYEK-623/2017).

One thousand fertile eggs were purchased from a commercial company (CP Standart Gida San.ve Tic. A.Ş, İstanbul, Turkey) and weighed with $0.1 \mathrm{~g}$ precision scales. After being checked for fracture, crack and structural defect, 960 eggs were distributed randomly to four treatment groups with six replicates (40 eggs at $45.6 \pm 3 \mathrm{~g}$ weight per replication) and placed in hatchery trays. The eggs were incubated (model T1280, Çimuka, Ankara, Turkey) under optimal conditions $\left(37.2{ }^{\circ} \mathrm{C}-37.7^{\circ} \mathrm{C}\right.$ and $60 \%-75 \%$ humidity) at the Research and Application Farm of Agricultural Faculty of Eskişehir Osmangazi University, Turkey. A $0.9 \%$ saline (Foye et al., 2006) was prepared and used in a 1\% ßA solution (Kop-Bozbay et al., 2018) (Sigma Alderich No. H8125 and A9920, MilliporeSigma, St. Louis, Missouri, USA). The treatment groups consisted of eggs that were not injected ( $\mathrm{T} 1$; negative control), injected with a sterile solution with $0.9 \%$ salt (T2; positive control), injected with in ovo $1 \% \beta A$ solution (T3), and not injected with the chicks being fed $1 \% \beta A$ feed during the first seven days after hatching (T4). The in ovo injection was accomplished by inserting $1 \mathrm{ml}$ of solution into the amnion with a 19-mm long and 27-gauge needle (Uni et al., 2005). The injection area was disinfected with ethyl alcohol and dressed with liqud paraffin, and then the eggs were transferred to hatching baskets. All these operations were completed in about five minutes.

Within two hours of hatching, the measurements related to hatching characteristics were ascertained. Then the chicks were transferred to an experimental house with six replicates of 28 birds (14 females and 14 males) with similar average weights $(42 \pm 3 \mathrm{~g}$ ) and reared for 42 days. Except for the T4 chicks, all groups were fed ad libitum with a corn-soybean-based commercial diet that was formulated according to NRC (1994) guidelines (Table 1). The T4 birds were fed with a $1 \% \beta A(10 \mathrm{~g} \beta A / \mathrm{kg})$ supplemented starter feed for the first seven days after hatching. The experiment was performed under standard husbandry practices, and the health status and general appearance of the birds were monitored at least twice daily.

To determine the yolk sac weight (YSW) and yolk-free bodyweight of the embryos (EW) on the 18th day of incubation and chick weight (CW) at hatch, six embryonated eggs and six chicks were selected, and bodyweight changes (BWC) were calculated. As soon as the hatching process was completed, the chicks were taken from the machine and were checked for abnormalities such as an unclosed belly and foot defects, and their bodyweights were recorded. At hatch, the chicks and all unhatched eggs were counted, and the chick quality scores (CQS) (Tona et al., 2003) of the weighed chicks were established. The percentage of hatchability was calculated following Ghanaatparast-Rashti et al. (2018):

$$
\% \text { hatchability }=\frac{\text { live chicks upon hatching }}{\text { number of fertile eggs obtained at day } 17}
$$

All unhatched eggs were opened, and dead chicks were evaluated as those that were fully formed, but dead without pipping, or as those that had pipped, but were dead in shell (Bhattacharyya et al., 2018). Dead chicks in each class were expressed as percentages of incubated fertile eggs. The time that elapsed from hatching until reaching feed was recorded for each chick (Aigueperse et al., 2013).

The broilers were weighed to determine BW on days 7,21 and 42, and the feed consumed (FI) between these time points was recorded. Feed conversion ratio (FCR) was calculated from these data.

At 42 days old, a total of 48 animals (one male and one female) were chosen at random from each replication, weighed, killed by cervical dislocation, and processed (Kop-Bozbay \& Ocak, 2015a). After removing the visceral contents, carcass weight was recorded. The carcass yield was calculated as $\mathrm{g} / 100 \mathrm{~g}$ bodyweight. The colour values ( $L^{*}$, lightness; $a^{*}$, redness; $b^{*}$, yellowness) of the skinless left breast (pectoralis muscle (PM) and thigh llio tibialis muscle (ITM) meats of each cleaned bird were measured with a Minolta CR 300 chroma meter (Minolta Camera, Osaka, Japan) at day 45. Three replicate measures were made at random locations on the raw PM and ITM, and the mean colour values were calculated for each sample. Immediately after colour measurement, $\mathrm{pH}$ values were assessed with a digital $\mathrm{pH}$ meter 
(Cyberscan PC 510), calibrated at $25^{\circ} \mathrm{C}$ and buffer solution at pH 4.01 and 7.00 (Mettler Toledo, USA) from three points of the PM and ITM (Von Lengerken et al., 2002). The meat samples $(1 \mathrm{~g})$ from the ITM and PM were rolled in filter paper, put in Eppendorf tubes, and centrifuged for $4 \min \times 1500 \mathrm{~g}$, then the water-holding capacity (WHC) was determined (Kop-Bozbay et al., 2020).

Table 1 Ingredients and nutrient composition of the basal diet (as-fed basis) provided to broiler chickens to determine the effects of supplemental beta alanine

\begin{tabular}{lcc}
\hline Ingredients $(\mathrm{g} / \mathrm{kg})$ & Starter (days 0 - 21) & Finisher (days 22 - 42) \\
\hline Corn & 552.50 & 587.00 \\
Soybean meal (46\%) & 380.00 & 330.00 \\
Vegetable oil & 25.00 & 45.00 \\
Dicalcium phosphate & 19.00 & 19.50 \\
Limestone & 12.00 & 7.50 \\
Sodium chloride & 4.00 & 3.50 \\
Lysine-HCL & 2.50 & 2.50 \\
DI-Methionine & 2.50 & 2.50 \\
Vitamin-mineral premix ${ }^{1}$ & 2.50 & 2.50 \\
\hline Calculated energy (MJ/kg) and nutrient contents $(\mathrm{g} / \mathrm{kg})$ & \\
\hline Metabolizable energy & 12.720 & 13.350 \\
Dry matter & 88.816 & 89.099 \\
Crude protein & 21.850 & 19.760 \\
Eter extract & 4.505 & 6.528 \\
Crude fibre & 2.909 & 2.787 \\
Ash & 6.176 & 5.787 \\
Lysine & 1.505 & 1.156 \\
Methionine & 0.579 & 0.514 \\
Methionine+cysteine & 0.921 & 0.867 \\
D-Tryptophan & 0.241 & 0.214 \\
Calcium & 0.960 & 0.900 \\
Available P & 0.400 & 0.400 \\
& & \\
\hline
\end{tabular}

'Vitamin A: $12000 \mathrm{IU}$, vitamin $\mathrm{D}_{3}: 2400 \mathrm{IU}$, vitamin $\mathrm{E}: 30 \mathrm{IU}$, vitamin $\mathrm{K}_{3}: 2.5 \mathrm{mg}$, vitamin $\mathrm{B}_{1}: 3.0 \mathrm{mg}$, vitamin $\mathrm{B}_{2}: 7 \mathrm{mg}$, nicotinamide: $40 \mathrm{mg}$, calcium D-pantothenate: $8.0 \mathrm{mg}$, vitamin $B_{6}: 4.0 \mathrm{mg}$; vitamin $\mathrm{B}_{12}: 0.015 \mathrm{mg}$; folic acid: $1 \mathrm{mg}$, dbiotine: $0.045 \mathrm{mg}$, vitamin c: $50 \mathrm{mg}$, chlorine chloride: $125 \mathrm{mg}$, manganese: $80 \mathrm{mg}$ : iron: $40 \mathrm{mg}$, zinc: $60 \mathrm{mg}$, copper: 5 $\mathrm{mg}$, cobalt: $0.1 \mathrm{mg}$, iodine: $0.4 \mathrm{mg}$, seleium: $0.15 \mathrm{mg}$

Total antioxidant status (TAS), total oxidant status (TOS), triglyceride, cholesterol, protein and glucose concentrations were calculated on days 7 and 42 from the blood of three males and three females, which was collected in heparinized tubes (Lin et al., 2006). The blood samples were centrifuged at $10^{\circ} \mathrm{C}$ for $10 \mathrm{~min}$ at $4000 \mathrm{rpm}$, and serum was harvested and stored at $-20^{\circ} \mathrm{C}$ until the samples were analysed. These metabolites were measured with commercial kits (Corticosterone ELISA Kit, Assay Designs, catalogue no 900,907, USA) for poultry in a private laboratory. The in vitro enzymatic colorimetric method was used to measure triglyceride, cholesterol, protein and glucose (Chand et al., 2018). Total oxidant status and TAS were assayed with Randox kit components (Miller, 1993). Calibration of the assay was done with 6-hydroxy2, 5, 7, and 8-tetramethylchroman-2-carboxylic acid (trolox). The results were expressed in $\mathrm{mmol} / \mathrm{L}$ trolox equivalent antioxidant capacity using a trolox standard curve that ranged from 0 to $2.29 \mathrm{mmol} / \mathrm{L}$. Measurements were carried out on RX Imola automatic biochemical analyser (Randox Laboratories Ltd., Crumlin, Dublin, Ireland) (Pascariu et al., 2017).

The data were analysed with SPSS (IBM SPSS Inc., version 21.0. IBM Corp., Armonk, NY). One-way analysis of variance was used to determine the effects of the treatments on BW, FI and FCR. The normal distribution of the data was evaluated with the Levene test, and the homogeneity of variance was tested with 
the Kolmogorov-Smirnov test. Differences between treatment means were assessed with Duncan's multiple comparison test when the analysis of variance produced significant effects. The probability $P<0.05$ was used as the critical value for establishing treatment effects.

\section{Results and Discussion}

The yolk-free CWs of T3 chicks were higher than T1, and their pre-hatch weight gain was higher than T4 $(P<0.05)$ (Table 2). At hatch, the T3 group had lower YSW than the T4 group $(P<0.05)$. The hatchability of T3 eggs was higher than T1 $(P<0.05)$. The embryonic mortality in T3 eggs was lower than in T1 and T2 $(P<0.05)$. T3 chicks had a higher CQS than the other groups $(P<0.05)$ and a lower feed access time than T1 and T4 chicks $(P<0.001)$. The lack of differences between in T2 wherein the eggs had been injected with saline (a sham treatment) and those eggs that were not injected ( $\mathrm{T} 1$ and $\mathrm{T} 4$ ) might be interpreted to suggest standard incubation procedures could be applied in nutritional studies that are conducted in ovo.

Table 2 Yolk-free embryo weight on day 18 of incumbation, yolk-free chick weight at hatching, yolk sac weight, bodyweight between day 18 of incubation and hatching, and hatchability trait responses to in ovo feeding of beta alanine to broilers

\begin{tabular}{lcccccc}
\hline Items & $\mathrm{T} 1$ & $\mathrm{~T} 2$ & $\mathrm{~T} 3$ & $\mathrm{~T} 4$ & $\mathrm{SE}$ & $P$-value \\
\hline Embryo weight at day 18, g & 29.76 & 30.11 & 29.87 & 30.58 & 0.248 & 0.688 \\
Chick weight at hatching, g & $34.13^{\mathrm{b}}$ & $34.45^{\mathrm{ab}}$ & $35.82^{\mathrm{a}}$ & $34.52^{\mathrm{ab}}$ & 0.232 & 0.038 \\
Weight change, g & $4.37^{\mathrm{ab}}$ & $4.34^{\mathrm{ab}}$ & $5.95^{\mathrm{a}}$ & $3.94^{\mathrm{b}}$ & 0.257 & 0.019 \\
Yolk sac weight at day 18, g & 12.93 & 13.50 & 13.64 & 13.43 & 0.276 & 0.840 \\
Yolk sac weight at hatch, g & $5.25^{\mathrm{ab}}$ & $5.15^{\mathrm{ab}}$ & $4.55^{\mathrm{b}}$ & $6.33^{\mathrm{a}}$ & 0.235 & 0.047 \\
Hatchability, \% & $89.96^{\mathrm{b}}$ & $91.05^{\mathrm{ab}}$ & $97.27^{\mathrm{a}}$ & $92.85^{\mathrm{ab}}$ & 0.770 & 0.044 \\
Pipped and dead, \% & $5.75^{\mathrm{a}}$ & $5.68^{\mathrm{a}}$ & $2.86^{\mathrm{b}}$ & $3.81^{\mathrm{ab}}$ & 0.437 & 0.033 \\
Dead and not pipped, \% & 4.29 & 3.27 & 1.87 & 3.33 & 0.390 & 0.177 \\
Chick quality score & $98.16^{\mathrm{b}}$ & $97.94^{\mathrm{b}}$ & $99.61^{\mathrm{a}}$ & $97.16^{\mathrm{b}}$ & 0.319 & 0.042 \\
Time to access feed, s & $298.50^{\mathrm{a}}$ & $245.16^{\mathrm{ab}}$ & $130.50^{\mathrm{b}}$ & $292.00^{\mathrm{a}}$ & 16.684 & $<0.001$ \\
\hline
\end{tabular}

\footnotetext{
${ }^{a, b}$ Within a row, means with a common superscript were not different at probability $P=0.05$

T1: eggs not injected, T2: eggs injected with $0.9 \%$ sterile saline solution, T3: eggs injected with $1 \%$ A solution, T4: eggs not injected, similar to $\mathrm{T} 1$ at hatching
}

The FI, BW and FCR of broiler chickens at days 7, 21 and 42 were not affected by in ovo feeding of $\beta A$ or its supplementation after hatch (Table 3 ). T3 and T4 produced birds with increased carcass yield at 42 days old compared with $\mathrm{T} 1,(P<0.05)$.

The PM was lighter in $L^{*}$ values $(P<0.001)$ in T3 and T4 than in the T1 birds. The $a^{*}$ value of PM from T1 and T3 birds was higher than in T4 birds $(P<0.001)$. The $L^{*}$ value of ITM from T4 birds was higher than for the other treatments, whereas $\mathrm{a}^{*}$ value of T3 birds was higher than birds in the T2 and T4 treatments $(P$ $<0.001$ ).

Blood parameters were not affected by $\beta A$ administration in ovo or in starter feed, except for the TAS value at 42 days old (Table 5). The T3 treatment increased the TAS value compared with the T1 treatment $(P<0.05)$. 
Table 3 Feed intake, bodyweight, feed conversion ratio and carcass yield responses to beta alanine $(\beta A)$ administered in ovo or fed to broilers for seven days after hatching

\begin{tabular}{lccccccc}
\hline \multicolumn{1}{c}{ Items } & Days & T1 & T2 & T3 & T4 & SE & $P$-value \\
\hline \multirow{2}{*}{ Feed intake, g } & 7 & 179.45 & 174.51 & 178.20 & 177.23 & 1.018 & 0.369 \\
& 21 & 1310.1 & 1315.7 & 1317.4 & 1334.7 & 13.28 & 0.931 \\
& 42 & 4264.6 & 4274.3 & 4126.0 & 4187.1 & 52.36 & 0.763 \\
Bodyweight, g & 7 & 145.95 & 140.51 & 142.08 & 137.95 & 1.456 & 0.258 \\
& 21 & 745.92 & 748.54 & 767.53 & 734.75 & 12.531 & 0.862 \\
& 42 & 2359.3 & 2397.4 & 2347.7 & 2267.7 & 30.59 & 0.467 \\
FCR & 7 & 1.23 & 1.24 & 1.25 & 1.28 & 0.012 & 0.466 \\
& 21 & 1.78 & 1.76 & 1.72 & 1.82 & 0.042 & 0.887 \\
Carcass yield, g/100g & 42 & 1.78 & 1.80 & 1.75 & 1.85 & 0.018 & 0.315 \\
& 42 & $70.27^{\mathrm{b}}$ & $72.20^{\text {ab }}$ & $73.40^{\mathrm{a}}$ & $74.16^{\mathrm{a}}$ & 0.544 & 0.049 \\
\hline
\end{tabular}

${ }^{a, b}$ Within a row, means with a common superscript were not different at probability $P=0.05 ; \beta A$ : beta alanine

T1: eggs not injected, T2: eggs injected with $0.9 \%$ sterile saline solution, T3: eggs injected with $1 \% \beta A$ solution, T4: chicks supplemented with $\beta A$ for seven days after hatching, FCR: feed conversion ratio

Table $4 \mathrm{pH}$, water-holding capacity and colour characteristics of breast and thigh meats in response to beta alanine administration in ovo or fed to broilers for seven days after hatching

\begin{tabular}{llcccccc}
\hline Items & & $\mathrm{T} 1$ & $\mathrm{~T} 2$ & $\mathrm{~T} 3$ & $\mathrm{~T} 4$ & $\mathrm{SE}$ & $\mathrm{P}$-value \\
\hline \multirow{2}{*}{ Breast muscle } & $\mathrm{pH}$ & $6.38^{\mathrm{b}}$ & $6.42^{\mathrm{ab}}$ & $6.52^{\mathrm{a}}$ & $6.44^{\mathrm{a}}$ & 0.031 & 0.014 \\
& $\mathrm{WHC} \%$ & 64.56 & 64.55 & 66.52 & 63.09 & 0.538 & 0.187 \\
& $\mathrm{CIE} \mathrm{L^{* }}$ & $55.32^{\mathrm{b}}$ & $58.40^{\mathrm{ab}}$ & $58.60^{\mathrm{a}}$ & $63.95^{\mathrm{a}}$ & 0.927 & 0.001 \\
& $\mathrm{CIE} \mathrm{a}^{*}$ & $4.18^{\mathrm{a}}$ & $3.01^{\mathrm{ab}}$ & $4.16^{\mathrm{a}}$ & $1.78^{\mathrm{b}}$ & 0.216 & 0.001 \\
& $\mathrm{CIE} \mathrm{b}^{*}$ & 7.47 & 6.21 & 7.44 & 7.36 & 0.480 & 0.380 \\
Thigh muscle & $\mathrm{pH}$ & 6.18 & 6.11 & 6.30 & 6.26 & 0.028 & 0.080 \\
& $\mathrm{WHC} \%$ & 63.06 & 63.46 & 62.66 & 64.70 & 0.572 & 0.629 \\
& $\mathrm{CIE} \mathrm{L}^{*}$ & $57.64^{\mathrm{b}}$ & $60.74^{\mathrm{b}}$ & $53.16^{\mathrm{b}}$ & $67.79^{\mathrm{a}}$ & 1.078 & $<0.001$ \\
& $\mathrm{CIE} \mathrm{a}^{*}$ & $1.81^{\mathrm{ab}}$ & $0.99^{\mathrm{b}}$ & $2.89^{\mathrm{a}}$ & $0.50^{\mathrm{b}}$ & 0.245 & $<0.001$ \\
& $\mathrm{CIE} \mathrm{b}^{*}$ & 4.93 & 5.40 & 6.80 & 6.31 & 0.281 & 0.369
\end{tabular}

\footnotetext{
${ }^{a, b}$ Within a row, means with a common superscript were not different at probability $P=0.05$

T1: eggs not injected, T2: eggs injected with $0.9 \%$ sterile saline solution, T3: eggs injected with $1 \% \beta A$ solution, T4: chicks supplemented with $\beta A$ for seven days after hatching, WHC: water-holding capacity, $\mathrm{CIE} \mathrm{L}^{*}$ : lightness (black $=0$ and white $=100$ ), $\mathrm{CIE} \mathrm{a}^{*}$ : green-red opponent colours $<0$ indicates greenness, $>0$ indicates redness, $\mathrm{CIE} \mathrm{b}^{*}$ : blue-yellow opponent colours ( $<0$ indicates blueness, $>0$ indicates yellowness)
}

Kop-Bozbay et al. (2018) observed that in ovo feeding of $\beta A$ at a dose of $0.75 \%$ increased $C W$ by $7.4 \%$. In the current study, T3 produced a $4.95 \%$ increase in $\mathrm{CW}$ at hatching compared with the control group. In addition, increased use of the yolk sac in T3 supported this rise in CW. This is consistent with findings that in ovo feeding with amino acids stimulated the use of the yolk by the embryo and consequently accelerated intestinal development (Kop-Bozbay \& Ocak, 2015b). In the present study, T3 stimulated the use of yolk sac significantly, so these chicks had less residual yolk sac at hatch. These findings are in line with the results of in ovo threonine feeding by Kadam et al. (2008). 
Table 5 Serum total oxidant status, total antioxidant status, triglyceride, cholesterol, protein, and glucose levels in response to beta alanine administration in ovo or fed to broilers for seven days after hatching

\begin{tabular}{|c|c|c|c|c|c|c|c|}
\hline Items & & $\mathrm{T} 1$ & $\mathrm{~T} 2$ & T3 & $\mathrm{T} 4$ & SE & $P$-value \\
\hline \multirow[t]{6}{*}{ Day 7} & Total antioxidant status, $(\mu \mathrm{mol} / \mathrm{l})$ & 0.44 & 0.90 & 1.06 & 1.34 & 0.156 & 0.200 \\
\hline & Total oxidant status, $(\mu \mathrm{mol} / \mathrm{l})$ & 20.82 & 14.69 & 20.39 & 16.40 & 1.903 & 0.634 \\
\hline & Glucose, mg/DI & 219.20 & 232.33 & 216.00 & 209.16 & 9.171 & 0.853 \\
\hline & Protein, mg/dL & 2.66 & 2.36 & 1.86 & 2.51 & 0.152 & 0.290 \\
\hline & Cholesterol, mg/DI & 153.60 & 179.66 & 165.1 & 177.83 & 9.206 & 0.753 \\
\hline & Triglyceride, mg/ dL & 51.00 & 56.00 & 44.16 & 56.33 & 2.519 & 0.332 \\
\hline \multirow[t]{6}{*}{ Day 42} & Total antioxidant status, $(\mu \mathrm{mol} / \mathrm{l})$ & $0.81^{\mathrm{b}}$ & $1.04^{\mathrm{ab}}$ & $1.36^{\mathrm{a}}$ & $1.24^{\mathrm{ab}}$ & 0.080 & 0.045 \\
\hline & Total oxidant status, $(\mu \mathrm{mol} / \mathrm{l})$ & 11.77 & 8.13 & 9.57 & 8.97 & 0.818 & 0.417 \\
\hline & Glucose, mg/dL & 218.50 & 222.16 & 231.50 & 231.50 & 3.506 & 0.638 \\
\hline & Protein, mg/dL & 2.23 & 2.16 & 2.16 & 2.10 & 0.045 & 0.759 \\
\hline & Cholesterol, mg/dL & 111.50 & 98.00 & 99.33 & 102.83 & 3.309 & 0.497 \\
\hline & Triglyceride, mg/dL & 42.50 & 34.66 & 34.00 & 42.33 & 2.080 & 0.298 \\
\hline
\end{tabular}

${ }^{a, b}$ Within a row, means with a common superscript were not different at probability $P=0.05$

T1: eggs not injected, T2: eggs injected with $0.9 \%$ sterile saline solution, T3: eggs injected with $1 \% \beta A$ solution, T4: chicks supplemented with $\beta A$ for seven days after hatching

Hatchability is an important criterion in determining the profitability of breeding companies and hatcheries. In the current study, T3 produced a $7.31 \%$ increase in hatchability and lower embryonic death compared with T1. The percentage hatchability seen in T1 exceeded the $87.2 \%$ level for normally shaped eggs (Kamanli et al., 2010). The number of chicks that hatch successfully is important, but so is chick quality. A chick of good quality (saleable) has been defined as being clean, dry, and free from deformities (Tona et al., 2003). Approximately $8 \%$ of hatched chicks may not be marketable (Tona et al., 2004). Assessment of chick quality is based on personal observation and subjective judgment with a scoring system defined in Tona et al. (2003). The Tona score has a positive correlation with bodyweight at six weeks old, and high scoring birds have the highest bodyweight when slaughtered. Therefore, hatching weight alone should not be considered a good indicator of chick quality (Decuypere \& Bruggeman, 2007). In the light of the present results (Table 2) and with supporting evidence from other studies (Kop-Bozbay et al., 2018; Araújo et al., 2019 ), it may be concluded that a higher number of chicks of better quality could be obtained with in ovo $\beta A$ injection on the 17th day of incubation. Therefore, chicks fed $\beta A$ in ovo are healthier and have higher life force than their unsupplemented counterparts (Tona et al., 2003; Decuypere \& Bruggeman, 2007). The reduced time from hatching to until the chicks accessed the feeder supports this suggestion. These findings support the conclusion that factors that affect protein synthesis and accumulation in the embryo influence the Tona score positively (Tona et al., 2003, 2004; Decuypere \& Bruggeman, 2007). In addition, chicks that have higher Tona scores would be more active and more willing to have feed, because they have a more functional digestive system at hatch.

Administration of $\beta A$ in in ovo or in starter feed did not affect bodyweight and feed consumption in the study, unlike the findings in Tomonaga et al. (2006); however, they do concur with Tomonaga et al. (2012). This difference between studies may depend on the type and line of poultry and the amount of $\beta A$ used in the experiments. Every gram of bodyweight difference at hatch has been associated with a $10 \mathrm{~g}$ difference in bodyweight at slaughter age (Vargas et al., 2009). In the present study, the increase in yolk-free hatching weight in T3 was not reflected in slaughter weight. However, the highest carcass yield was obtained from the T3 group.

The influence of $\beta A$ administration on the colour values of thigh and breast meats in the present study was in accord with a study in which $\beta A$ was added to the diet (Kralik et al., 2014). In contrast to the current study, Kralik et al. (2014) and Qi et al. (2018) reported that the $\mathrm{pH}$ value of PM did not change with the addition of $\beta A$. Kralik et al. (2014) and Qi et al. (2018) also reported that there was no difference in WHC of the breast and thigh muscles, in agreement with the present results. Meat colour and $\mathrm{pH}$ relate to many properties of chicken meat (lqbal et al., 2013). Low final pH in chicken PM causes pale (high L* values), soft, exudative meat (PSE) (Van Laack et al., 2000). When the current results were evaluated, it could be said 
that the breast and thigh muscles from birds that were provided with supplemental $\beta A$ were normal and there was no evidence of PSE.

Because the blood TAS level at slaughter age in the T3 group was higher than that of the poultry in T1 group, this may have been caused by the increase in the concentration of carnosine, which has strong antioxidant ability (O'Neill et al., 1998; Cong et al., 2017; Kralik et al., 2018; Qi et al., 2018; Kopec et al., 2020; Shimamoto et al., 2020). These studies reported that the antioxidant capacity of the PM increased with the $\beta A$ supplement (Qi et al., 2018). Therefore, although the muscle antioxidant properties were not identified, the antioxidant capacity in the muscles may have increased because of the rise in blood TAS. Thus, it can be concluded that the shelf life of broiler meats could be increased by $\beta A$ administration.

\section{Conclusion}

In ovo feeding with a $1 \%$ solution of $\beta A$ on the 17 th day of incubation (T4) can result in the production of more and healthier chicks. Dietary supplementation with $\beta A$ and in ovo feeding of $\beta A$ can also increase the carcass yield. Thus, $\beta A$ could be used beneficially in broiler production. In addition, standard incubation procedures could be applied in nutritional studies that are conducted in ovo because there were no differences in any of the measured variables between sham injected and non-injected eggs.

\section{Acknowledgements}

This research was part of an MSc project of the first author and was supported by the Scientific Research Fund of Eskisehir Osmangazi University (BAP 201723A122). The authors are grateful for the support of the staff and facilities of Animal Science Department, Agriculture Faculty, Eskisehir Osmangazi University. They thank Dr. Dilber E. for reviewing the manuscript and the Scientific Research Fund of Eskisehir Osmangazi University for providing the laboratory infrastructure (BAP 201723E03).

\section{Authors' Contributions}

CKB was responsible for the concept, formulation of objectives and scope of research, formulation of conclusions, and creation of the publication text. HA co-conducted the laboratory studies and implemented the research.

\section{Conflict of Interest Declaration}

The authors declare that they have no conflicts of interest relative to this research.

\section{References}

Aigueperse, N., Calandreau, L. \& Bertin, A., 2013. Maternal diet influences offspring feeding behavior and fearfulness in the precocial chicken. PloS one, 8. DOI: 10.1371/journal.pone.0077583

Araújo, I.C., Café, M.B., Noleto, R.A., Martins, J.M., Ulhoa, C.J., Guareshi, G.C. \& Leandro, N.S., 2019. Effect of vitamin $E$ in ovo feeding to broiler embryos on hatchability, chick quality, oxidative state, and performance. Poult. Sci. 98, 3652-3661. DOI: 10.3382/ps/pey439

Bhattacharyya, A., Majumdar, S., Bhanja, S.K., Mandal, A.B. \& Kadam, M., 2018. Effect of maternal dietary manipulation and in ovo injection of nutrients on the hatchability indices, post-hatch growth, feed consumption, feed conversion ratio and immunocompetence traits of turkey poults. J. Appl. Poult. Res. 46, 287-294. DOI: $10.1080 / 09712119.2017 .1296843$

Boldyrev, A.A., Aldini, G. \& Derave, W., 2013. Physiology and pathophysiology of carnosine. Physiol. Rev. 93, 1803-1845. DOI: $10.1152 /$ physrev.00039.2012

Chand, N., Naz, S., Rehman, Z. \& Khan, R.U., 2018. Blood biochemical profile of four fast-growing broiler strains under high ambient temperature. Appl. Biol. Chem. 61, 273-279. DOI: 10.1007/s13765-018-0358-4

Cong, J., Zhang, L., Li, J., Wang, S., Gao, F. \& Zhou, G., 2017. Effects of dietary supplementation with carnosine on meat quality and antioxidant capacity in broiler chickens. Br. Poult. Sci. 58, 69-75. DOI: $10.1002 /$ jsfa. 8236

Decuypere, E. \& Bruggeman, V., 2007. The endocrine interface of environmental and egg factors affecting chick quality. Poult. Sci. 86, 1037,1042. DOI: 10.1093/ps/86.5.1037

Elwan, H.A., Elnesr, S.S., Xu, Q., Xie, C., Dong, X. \& Zou, X., 2019. Effects of in ovo methionine-cysteine injection on embryonic development, antioxidant status, IGF-I and tIr4 gene expression, and jejunum histomorphometry in newly hatched broiler chicks exposed to heat stress during incubation. Anim. 9, 25. DOI: 10.3390/ani9010025

Foye, O.T., Uni, Z., Ferket, P.R. \& McMurtry, J.P., 2006. The effects of amniotic nutrient administration, in ovo feeding of arginine and/or-hydroxy-beta-methyl butyrate (HMB) on insulin-like growth factors, energy metabolism and growth in turkey poults. J. Poult. Sci. 5, 309-317. DOI: 10.3923/ijps.2006.309.317

Ghanaatparast-Rashti, M., Mottaghitalab, M. \& Ahmadi, H., 2018. In ovo feeding of nutrients and its impact on post-hatching water and feed deprivation up to $48 \mathrm{hr}$, energy status and jejunal morphology of chicks using response surface models. J. Anim. Physiol. Anim. Nutr. 102, 806-817. DOI: 10.1111/jpn.12838

Iqbal, A., Sun, D.W. \& Allen, P., 2013. Prediction of moisture, color and pH in cooked, pre-sliced turkey hams by NIR hyperspectral imaging system. J. Food Eng. 117, 42-51. DOI: 10.1016/j.jfoodeng.2013.02.001

Kadam, M. M., Bhanja, S.K., Mandal, A.B., Thakur, R., Vasan, P., Bhattacharyya, A. \& Tyagi, J. S., 2008. Effect of in ovo threonine supplementation on early growth, immunological responses and digestive enzyme 
activities in broiler chickens. Br. Poult. Sci. 49 6, 736-741. DOI: 10.1080/00071660802469333

Kamanli, S., Durmus, I. \& Demir, S., 2010. Hatching characteristics of abnormal eggs. Asian J. Vet. Adv. 5, 271 274. DOI: 10.3923/ajava.2010.271.274

Kop-Bozbay, C. \& Ocak, N., 2015a. Body weight, meat quality and blood metabolite responses to carbohydrate administration in the drinking water during pre-slaughter feed withdrawal in broilers. J. Anim. Physiol. Anim. Nutr. 99, 290-298. DOI: 10.1111/jpn.12194

Kop-Bozbay, C. \& Ocak, N., 2015b. Growth, digestive tract and muscle weights in slow-growing broiler is [sic] not affected by a blend of branched-chain amino acids injected into different sites of egg. J. Agric. Environ. Sci. 4, 261-269. DOI: 10.15640/jaes.v4n1a32

Kop-Bozbay, C. \& Ocak, N., 2019. In ovo injection of branched-chain amino acids: Embryonic development, hatchability and hatching quality of turkey poults. J. Anim. Physiol. Anim. Nutr. 103, 1135-1142. DOI: 10.1111/jpn.13111

Kop-Bozbay, C. \& Ocak, N., 2020. Posthatch development in response to branched-chain amino acids blend supplementation in the diet for turkey poults subjected to early or delayed feeding. J. Anim. Plant Sci. 30, 1098-1105. DOI: 10.36899/JAPS.2020.5.0125

Kop-Bozbay, C., Akdağ, A., Atan, H. \& Ocak, N., 2018. Hatchability, some hatchling parameters, quality score, survivability in newly hatched-broiler chicks receiving a $\beta$-Alanine solution in ovo. Turkish J. Agric. Food Sci. Technol, 6, 1469-1473. DOI: 10.24925/turjaf.v6i10.1469-1473.2083

Kop-Bozbay, C., Akdag, A., Atan, H. \& Ocak, N., 2020. Response of broilers to supplementation of branchedchain amino acids blends with different valine contents in the starter period under summer conditions. Asian-Australas J. Anim. Sci. DOI: 10.5713/ajas.19.0828

Kopec, W., Jamroz, D., Wiliczkiewicz, A., Biazik, E., Pudlo, A., Korzeniowska, M. \& Skiba, T., 2020. Antioxidative characteristics of chicken breast meat and blood after diet supplementation with carnosine, L-histidine, and $\beta$-alanine. Antioxidants 9, 1093. DOI: 10.3390/antiox9111093

Kralik, G., Sak-Bosnar, M., Kralik, Z. \& Galović, O., 2014. Effects of $\beta$-alanine dietary supplementation on concentration of carnosine and quality of broiler muscle tissue. J. Poult. Sci. 51, 151-156. DOI: 10.2141/jpsa.0130047

Kralik, G., Sak-Bosnar, M., Grčević, M. \& Kralik, Z., 2018. Effect of amino acids on growth performance, carcass characteristics, meat quality, and carnosine concentration in broiler chickens. J. Poult. Sci. 55, 239-248. DOI: 10.2141/jpsa.0170083

Kralik, G., Sak-Bosnar, M., Kralik, Z., Galović, O., Grčević, M. \& Kralik, I., 2015. Effect of $\beta$-alanine and Lhistidine on concentration of carnosine in muscle tissue and oxidative stability of chicken meat. Polio Privreda, 21, 190-194. DOI: 10.18047/poljo.21.1.sup.45

Lin, H., Decuypere, E. \& Buyse, J., 2006. Acute heat stress induces oxidative stress in broiler chickens. Comparative Biochemistry and Physiology Part A: Mol. Integ. Physiol. 144, 11-17. DOI: 10.1016/j.cbpa.2006.01.032

Miller, N.J., Rice-Evans, C., Davies, M.J., Gopinathan, V. \& Milner, A., 1993. A novel method for measuring antioxidant capacity and its application to monitoring the antioxidant status in premature neonates. Clinical Science 84, 407-412. DOI: $10.1042 / \operatorname{cs} 0840407$

NRC, 1994. Nutrient requirements of poultry. 9th rev. edn. National Academy Press, Washington.

O'Neill, L.M., Galvin, K., Morrissey, P.A. \& Buckley, D.J., 1998.Inhibition of lipid oxidation in chicken by carnosine and dietary a-tocopherol supplementation and its determination by derivative spectrophotometry. Meat Sci. 50, 479-488. DOI: 10.1016/s0309-1740(98)00061-8

Qi, B., Wang, J., Ma, Y.B., Wu, S.G., Qi, G.H. \& Zhang, H.J., 2018. Effect of dietary $\beta$-alanine supplementation on growth performance, meat quality, carnosine content, and gene expression of carnosine-related enzymes in broilers. Poult. Sci. 97, 1220-1228. DOI: 10.3382/ps/pex410

Pascariu, S.M., Pop, I.M., Simeanu, D., Pavel, G. \& Solcan, C., 2017. Effects of wine by-products on growth performance, complete blood count and total antioxidant status in broilers. Braz. J. Poultry Sci. 19, 191202. DOI: 10.1590/1806-9061-2016-0305

Shimamoto, S., Nakamura, K., Tomonaga, S., Furukawa, S. Ohtsuka, A. \& ljiri, D., 2020. Effects of cyclic high ambient temperature and dietary supplementation of orotic acid, a pyrimidine precursor, on plasma and muscle metabolites in broiler chickens. Metabolites 10, 189. DOI: 10.3390/metabo10050189

Sirsat, S.D., Chathrashree, A.R., Ramteke, B.N. \& Shirsat, S.D., 2018. Early post hatch feeding in chicks and practical constrains [sic] - A review. Agric. Rev. 39, 226-233. DOI: 10.18805/ag.R-1763

Tavaniello, S., Slawinska, A., Prioriello, D., Petrecca, V., Bertocchi, M., Zampiga, M., Salvatori, G. \& Maiorano, G., 2020. Effect of galactooligosaccharides delivered in ovo on meat quality traits of broiler chickens exposed to heat stress. Poult. Sci. 99, 612-619. DOI: 10.3382/ps/pez556

Tomonaga, S., Kaji, Y., Tachibana, T., Denbow, D.M. \& Furuse, M., 2005. Oral administration of $\beta$-alanine modifies carnosine concentrations in the muscles and brains of chicken. Anim. Sci. J. 76, 249-254. DOI: 10.1111/j.1740-0929.2005.00263.x

Tomonaga, S., Matsumoto, M. \& Furuse, M., 2012. $\beta$-Alanine enhances brain and muscle carnosine levels in broiler chicks. J. Poult. Sci. 0110165. DOI: 10.2141/jpsa.0110165

Tomonaga, S., Kaneko, K., Kaji, Y., Kido, Y., Denbow, D.M. \& Furuse, M., 2006. Dietary $\beta$-alanine enhances brain, but not muscle, carnosine and anserine concentrations in broilers. Anim. Sci. J. 77, 79-86. DOI: 10.1111/j.1740-0929.2006.00323.x

Tona, K., Onagbesan, O., De Etelaere, B., Decuypere, E. \& Bruggeman, V., 2004. Effects of age of broiler 
breeders and egg storage on egg quality, hatchability, chick quality, chick weight, and chick posthatch growth to forty-two days. J. Appl. Poult. Res. 13, 10-18. DOI: 10.1093/japr/13.1.10

Tona, K., Bamelis, F., De Ketelaere, B., Bruggeman, V., Moraes, V.M., Buyse, J., Onagbesan, O. \& Decuypere, E., 2003. Effects of egg storage time on spread of hatch, chick quality, and chick juvenile growth. Poult. Sci. 82, 736-741. DOI: 10.1093/ps/82.5.736

Uni, Z., Ferket, P.R., Tako, E. \& Kedar, O., 2005. In ovo feding improves energy status of late-term chicken embryos. Poult. Sci. 84, 764-770. DOI: 10.1093/ps/84.5.764

Van Laack, R.L.J.M., Liu, C.H., Smith, M.O. \& Loveday, H.D., 2000. Characteristics of pale, soft, exudative broiler breast meat. Poult. Sci. 79, 1057-1061. DOI: 10.1093/ps/79.7.1057

Vargas, G.E., Mesones, R.V., Bretcanu, O., López, J.M.P., Boccaccini, A.R. \& Gorustovich, A., 2009. Biocompatibility and bone mineralization potential of $45 \mathrm{~S} 5$ Bioglass $\AA$-derived glass-ceramic scaffolds in chick embryos. Acta Biomaterialia, 5, 374-380. DOI: 10.1016/j.actbio.2008.07.016

Von Lengerken, G., Maak, S. \& Wicke, M., 2002. Muscle metabolism and meat quality of pigs and poultry. Veterinariia ir Zootecknika. 20, 82-86.

Wu, G., 2020. Important roles of dietary taurine, creatine, carnosine, anserine and 4-hydroxyproline in human nutrition and health. Amino Acids 52, 329-360. https://doi.org/10.1007/s00726-020-02823-6 